tại các bệnh viện để mở rộng nghiên cứu đánh giá hiệu quả của các thuốc.

\section{TÀI LIÊU THAM KHẢO}

1. Canavan C. et al. The epidemiology of irritable bowel syndrome. Clinical epidemiology. 2014. 6:71.

2. Võ Thị Thuý Kiêu, Bùi Thi Hương Quỳnh, Võ Duy Thông. Khảo sát viêc điêuu trị hôi chứng ruôt kích thích tại bệnh viện Nhân Dân Gia Định. Tạp chí Y hoc TP. Hồ Chí Minh. 2015. 19: 760-765.

3. Agarwal $\mathbf{N}$, Spiegel BM. The effect of irritable bowel syndrome on health-related quality of life and health care expenditures. Gastroenterology Clinics. 2011; 40(1):11-19

4. Doan Phan Ngoc Thao, Nguyen Ngoc Phuc, Vo Duy Thong, Bui Thi Huong Quynh. Investigation of quality of life and factors related to quality of life of patients with irritable bowel syndrome. Vietnam Journal of Medicine and Pharmacy. 2018. 23(2):227-233.

5. Jarrett ME, Cain KC, Burr RL, et al. Comprehensive self-management for irritable bowel syndrome: Randomized trial of in-person versus combined in-person and telephone sessions. The American Journal of Gastroenterology. 2009. 104(12):3004

6. Schneider A, Rosenberger S, Bobardt J. Selfhelp guidebook improved quality of life for patients with irritable bowel syndrome. PloS One. 2017. 12(7): e0181764.

7. Dorn SD, Palsson OS, Woldeghebriel $M$, et al. Development and pilot testing of an integrated, web-based self-management program for irritable bowel syndrome (IBS). Neurogastroenterology \& Motility. 2015; 27(1):128-134.

\title{
CHI PHÍ TRỰC TIẾP ĐIỀU TRI UNG THƯ GAN TẠI VIỆT NAM, NĂM 2019
}

\section{TÓM TẮT}

Mục tiêu: Nghiên cứu được thực hiện nhằm đo lường chi phí trực tiếp điều trị ung thư gan tại Việt Nam năm 2019. Phương pháp nghiên cứu: Nghiển cứu mô tả cắt ngang, dựa trên hồi cứu số liệu từ hồ sơ thanh toán khi ra viện và phỏng vấn 90 người bệnh ung thư gan hoàn thành đợt điều trị trong thời gian thu thâp số liệu của nghiên cứu, từ tháng 12/2019 đến tháng 6/2020 tại bệnh viện K Trung Ương. Kết quả và kết luân: Nghiên cứu cho thấy, trong đợt điều trị hiện tại, tổng chi phí trực tiếp vào khoảng 47.305.000 VNE் với chi phí thấp nhất là 12.957.000 VNĐ và chi phí cao nhất là 111.680.000 VNĐ. Đối với tổng chi phí trong năm 2019, tổng chi phí trực tiếp trung bình lên đến tổng chi phí trực tiếp vào khoảng 250.857.000 VNĐ với chi phí thấp nhất là 31.288.000 VNĐ và chi phí cao nhất là 1.291.727.000 VNĐ. Trong các nhóm chi phí, chi phí tiền túi hộ gia đình đều chiếm tỷ trong lớn hơn. Việt Nam

Tư khoá: Chi phí điều trị trực tiếp, ung thư gan,

\section{SUMMARY}

\section{DIRECT COST OF LIVER CANCER} TREATMENT IN VIETNAM, 2019

Objective: To measure the direct cost of liver cancer treatment in Vietnam in 2019. Methods: Cross-sectional descriptive study, based on

*Trường Đại học Y tế Công Cộng

Chịu trách nhiệm chính: Nguyễn Quỳnh Anh

Email: nqa@huph.edu.vn

Ngày nhận bài: 4.3.2021

Ngày phản biện khoa học: 20.4.2021

Ngày duyệt bài: 28.4.2021

\section{Nguyễn Quỳnh Anh*, Nguyễn Thu Hà*}

retrospective billing data from hospital discharge records and interviews with 90 liver cancer patients who completed treatment during data collection of the study, from December 2019 to June 2020 at Vietnam National Cancer Hospital. Results and conclusions: During the current treatment, the total direct cost was about 47,305,000 VND with the lowest cost of $12,957,000$ VND and the highest cost of $11,680,000$ VND. For total costs in 2019, the average total direct costs amount to VND 250,857,000 with the lowest cost of VND $31,288,000$ and the highest cost of VND $1,291,727,000$. Among the cost groups, household out-of-pocket expenses accounted for a larger share.

Keywords; Direct treatment costs, liver cancer, Vietnam

\section{I. ĐĂT VẤN ĐỀ}

Ở cả hai giới, ung thư gan đứng hàng đầu với tỷ lệ $15,4 \%$ tổng số mới mắc ung thư, tiếp đến là ung thư phổi, dạ dày, vú, đại trực tràng. Các bệnh phổ biến ở nam giới là ung thư gan, ung thư phổi, ung thư dạ dày, ung thư đại trực tràng và ung thư vòm họng, trong khi các bệnh phổ biến ở nữ giới lần lượt là ung thư gan, ung thư phổi, ung thư vú, ung thư dạ dày và ung thư cổ tử cung. Nghiên cứu gánh nặng bệnh tật tại Việt Nam năm 2017 cũng chỉ ra ung thư phổi, ung thư gan, ung thư đại trực tràng là 3 nhóm bệnh ung thư có gánh nặng hàng đầu trong nhóm bệnh ung thư $(1,2,3)$.

Trong điều kiện nguồn lực hạn chế, chi phí các dịch vụ y tế tăng cao, sự già hóa dân số và nhu câu chăm sóc sức khỏe tăng lên không ngừng, các nhà hoạch định chính sách phải cân 
nhắc lựa chọn các can thiệp mang lại hiệu quả tối ưu đồng thời cân đối với sự công bằng trong tiếp cận dịch vụ (4). Thông tin về các vấn đề sức khỏe bao gôm đối tượng chịu tác động, quy mô, nguyên nhân, gánh nặng kinh tế và gánh nặng bệnh tật đóng vai trò rất quan trọng trong quá trình xây dựng chính sách và thiết lập ưu tiên (4). Tại Việt Nam, trong bối cảnh ung thư là một trong những nguyên nhân hàng đâuu của gánh nặng bệnh tật và tử vong tại Việt Nam, việc thực hiện những nghiên cưuu nói trên sẽ cung cấp bằng chứng chính xác, có tính khoa học cao vê chi phí trực tiếp, chi phí gián tiếp và gánh nặng kinh tễ của một số bệnh ung thư phổ biến tại Việt Nam; từ đó cung cấp đây đủ thông tin cho các nhà hoạch định chính sách trong việc huy động, phân bổ nguồn lực cho hoạt động phòng chống ung thư trong hiện tại và tương lai.

Vì những lý do trên, nhằm cung cấp những bằng chứng đáng tin cậy giúp huy động và phân bổ nguôn lực trong kiểm soát ung thư cũng như làm tiền để cho các nghiên cứu về kinh tế y tế trong thời gian tới, nhóm nghiên cứu tiến hành đề tài nghiên cứu "Đo lường chi phí điều trị trực tiếp của ung thu gan tại Việt Nam năm 2019".

II. Đốı TƯợNG VÀ PHƯƠNG PHÁP NGHIÊN CỨU

Thiết kế nghiên cứu: Nghiên cứu cắt ngang sử dụng số liệu định lượng

Đối tượng nghiên cứu: Được chẩn đoán mắc ung thư gan (Liver Cancer, C22), tại thời điểm tiến hành phỏng vấn, người bệnh được chỉ định là đã hoàn thành đợt điều trị hiện tại

Thời gian và địa điểm nghiến cứu: từ tháng 12/2019 đến tháng 6/2020 tại bệnh viện K TW.

Cõ mẫu: Áp dụng công thức tính cỡ mẫu ước lượng giá trị trung bình

$$
\mathrm{N}=\frac{\frac{z_{\mathrm{l}-\alpha / 2}^{2} \sigma^{2}}{\varepsilon^{2} \mu^{2}}}{{ }^{2}}
$$

N: Là số đối tượng cân điều tra, Z: Hệ số tin cậy (Với độ tin cậy 95\% thì giá trị của Z = 1,96), б: Giá trị ước lượng của độ lệch chuẩn của đặc tính nghiên cứu trong quân thể, $\varepsilon$ : Độ chính xác tương đối, $\mu$ : Giá trị trung bình của đặc tính nghiên cứu trong quân thể

Sử dụng số liệu về giá trị trung bình và độ lệch chuẩn của 1 năm điều trị của bệnh ung thư gan trong nghiên cứu "Gánh nặng kinh tế của một số bệnh ung thư phổ biến tại Việt Nam năm 2012" (5) do Trường Đại học Y tế cống cộng và Bệnh viện $\mathrm{K}$ Trung ương phối hợp thực hiện năm 2013 là $\mu=47$ triệu đồng và $\sigma=40$ triệu đồng; lấy $\varepsilon=0,2$ thì số lượng người bệnh ung thư cần thiết đưa vào nghiển cứu ước tính cho nhóm bệnh ung thư gan là $N=70$. Thực tế thu thập được số liệu trên 90 người bệnh.

Phương pháp thu thập số liệu: Sử dụng Bảng hỏi có cấu trúc để phỏng vẩn toàn bộ người bênh ung thư thỏa mãn tiêu chí nghiên cứu chuẩn bị ra viện vào thời điểm diễn ra nghiên cứu, Bảng kiểm có sẵn để thu thập thông tin liên quan đến số lượng dịch vụ sử dụng và chi phí điều trị của người bệnh được thu thập từ phiếu thanh toán ra viện của bệnh nhân. Các nhóm chi phí được thu thập bao gồm: C1 - Chi phí trực tiếp dành cho y tế - từ phía CSYT/Chính phủ, C2 - Chi phí trực tiếp dành cho y tế - từ phía người bệnh/BHYT, C3 - Chi phí trực tiếp không dành cho y tế - từ phía người bệnh, C4 - Chi phí trực tiếp không dành cho y tế - từ phía gia đình.

Quản lý và phân tích số liệu: Số liệu được nhập bằng phần mêm Excel 2007 cho phẩn thông tin liên quan đến bệnh viện và phân mềm Epi data 3.1 cho các thống tin liên quan đến người bệnh.

Đạo đức nghiên cứu: Nghiên cứu tuân thủ quy trình xét duyệt của Hội đồng nghiên cứu khoa học Trường Đại học Y tế công cộng.

\section{KẾT QUẢ NGHIÊN CỨU}

1. Thông tin chung của đối tượng nghiên cứu

Bảng 1: Mô tả các thông tín cơ bản về người bệnh tham gia trả lời phỏng vấn

\begin{tabular}{|c|c|c|}
\hline Đăc điểm & Tân số (n) & Tỷ lê(\%) \\
\hline Nhóm tuối: 15-30 & 3 & $3,3 \%$ \\
\hline $31-45$ & 10 & $11,1 \%$ \\
\hline $46-60$ & 46 & $51,1 \%$ \\
\hline$>60$ & 31 & $34,4 \%$ \\
\hline Giới tính: Nũ & 72 & $80,0 \%$ \\
\hline Nam & 18 & $20,0 \%$ \\
\hline
\end{tabular}

Tình trạng hôn nhân

\begin{tabular}{|c|c|c|}
\hline Chưa kết hôn & 5 & $5,6 \%$ \\
\hline Đã kết hôn & 77 & $85,5 \%$ \\
\hline Góa & 5 & $5,6 \%$ \\
\hline Ly dị/ly thân & 3 & $3,3 \%$ \\
\hline \multicolumn{3}{|l|}{ Trình độ học vấn } \\
\hline Chưa hết tiểu học & $14(15,6 \%)$ & $15,6 \%$ \\
\hline Hết tiểu học & $19(21,1 \%)$ & $21,1 \%$ \\
\hline Hết trung học cơ sở & $27(30,0 \%)$ & $30,0 \%$ \\
\hline Hết trung học phố thông & $11(12,2 \%)$ & $12,2 \%$ \\
\hline $\begin{array}{c}\text { Cao đằng, trung cấp } \\
\text { nghề }\end{array}$ & $9(10,0 \%)$ & $10,0 \%$ \\
\hline Đại học và trên đại học & $10(11,1 \%)$ & $11,1 \%$ \\
\hline \multicolumn{3}{|c|}{ Tình trạng làm việc hiện tại } \\
\hline $\begin{array}{c}\text { Thất nghiệp/không làm } \\
\text { việc }\end{array}$ & $30(33,3 \%)$ & $33,3 \%$ \\
\hline Hưu trí & $10(11,1 \%)$ & $11,1 \%$ \\
\hline
\end{tabular}




\begin{tabular}{|c|c|c|}
\hline Đang có việc làm & $50(55,6 \%)$ & $55,6 \%$ \\
\hline BHYT: Không & $6(6,7 \%)$ & $6,7 \%$ \\
\hline Có & $84(93,3 \%)$ & $93,3 \%$ \\
\hline
\end{tabular}

Tổng số người bệnh ung thư gan tham gia trả lời phỏng vấn là 90 người bệnh. Về độ tuổi, độ tuổi trung bình của người bệnh tham gia phỏng vấn là $55,7( \pm 12,2)$ với độ tuổi thấp nhất là 15 tuổi và độ tuổi cao nhất là 83 tuổi. Người bệnh từ 46-60 tuổi chiếm tỷ lệ cao nhất $(51,1 \%)$, tiếp đến nhóm tuổi trên $60(34,4 \%)$, nhóm tuổi từ 31-45 (chiếm 11,1\%), thấp nhất là nhóm tuổi dưới 30 (3,3\%). Trong số người bệnh tham gia trả lời phỏng vấn, người bệnh nữ chiếm đa số $(80 \%)$. Đồng thời, đa số người bệnh tham gia trả lời phỏng vấn đã kết hôn $(85,6 \%)$. Còn lại là một tỷ lệ nhỏ chưa kết hôn $(5,6 \%)$, góa $(5,6 \%)$ và ly dị/ly thân $(3,3 \%)$.

Về trình độ học vấn, có $15,6 \%$ người bệnh chưa học hết tiểu học, 21,1\% người bệnh đã học hết tiểu học, 30,0\% người bệnh đã học hết trung học cơ sở, 12,2\% người bệnh đã học hết trung học phổ thông, $10,0 \%$ đã học hểt cao đẳng/trung cấp và $11,1 \%$ có trình độ đại học/ trên đại học. Thu nhập hộ gia đình của nhóm người bệnh ung thư gan là 97.884 .000 đồng/năm. Số ngày điều trị trung bình là 25,5 ngày dao động từ 1 đến 135 ngày.

\section{Chi phí điêu trị ung thư gan tại Việt} Nam năm 2019

Bảng 2 mô tả chi phí trung bình của người bênh ung thư gan trong nghiên cứu. Trong đợt điều trị hiện tại, tổng chi phí trực tiếp vào khoảng 47.305.000 VNĐ với chi phí thấp nhất là 12.957.000 VNĐ và chi phí cao nhất là 111.680.000 VNĐ. Giá trị Q1 là 28.814.000 VNĐ, chi phí trung vị cho đợt điều trị hiện tại là 43.594.000 VNĐ và giá trị Q3 tương ứng là 60.293.000 VND.

\section{Bảng 2: Chi phí trung bình của người bệnh ung thư gan trong nghiên cứu}

\begin{tabular}{|c|c|c|c|c|c|c|c|}
\hline & Mean & SD & Min & Q1 & Median & Q3 & Max \\
\hline \multicolumn{8}{|c|}{ Chi phí cho đơơt điều trị hiện tại } \\
\hline Chi tiền túi hộ gia đình & 30.186 & 22.240 & 689 & 15.586 & 24.965 & 40.306 & 96.859 \\
\hline Chi phí BHYT & 17.118 & 10.131 & 0 & 11.305 & 14.462 & 23.553 & 47.628 \\
\hline Tống chi trực tiếp & 47.305 & 25.680 & 12.957 & 28.814 & 43.594 & 60.293 & 111.680 \\
\hline \multicolumn{8}{|c|}{ Tống chi phí trong năm 2019 } \\
\hline Chi tiền túi hộ gia đình & 173.482 & 195.425 & 10.107 & 51.128 & 103.899 & 197.670 & 1.045 .779 \\
\hline Chi phí BHYT & 77.375 & 78.329 & 0 & 28.076 & 53.083 & 100.690 & 411.716 \\
\hline Tống chi trực tiếp & 250.857 & 256.884 & 31.288 & 98.321 & 159.190 & 297.280 & 1.291 .727 \\
\hline
\end{tabular}

Đối với tổng chi phí trong năm 2019, tổng chi phí trực tiếp trung bình lên đến tổng chi phí trực tiếp vào khoảng 250.857.000 VNĐ với chi phí thấp nhất là 31.288.000 VNĐ và chi phí cao nhất là 1.291.727.000 VNĐ. Giá trị Q1 là 98.321.000 VNĐ, chi phí trung vị cho đợt điều trị hiện tại là 159.190.000 VNĐ và giá trị Q3 tương ứng là 297.280.000 VND.

Hình 1 minh họa các cấu phần chi phí trong tổng chi phí cho đợt điều trị hiện tại và tổng chi phí trong năm 2019. Trong các nhóm chi phí, chi phí tiền túi hộ gia đình đều chiếm tỷ trọng lớn hơn. Cụ thể, đối với chi phí cho đợt điều trị hiện tại, chi phí tiền túi hộ gia đình và chi phí từ phía BHYT lần lượt chiếm $63,8 \%$ và $36,2 \%$. Đối với chi phí trong năm 2019, chi phí tiền túi hộ gia đình và chi phí từ phía BHYT lần lượt chiếm $69,2 \%$ và $30,8 \%$.

300.000

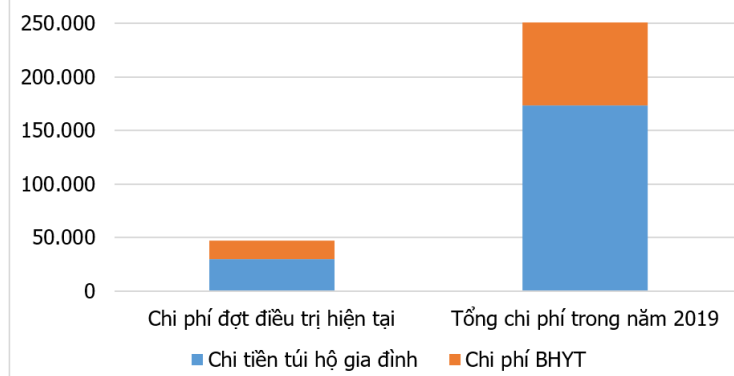

Hình 1: Tỷ lệ các nhóm chi phí của người bệnh ung thưgan

Bảng 3: Tỷ lệ các nhóm chi phí của người bệnh ung thư gan trong nghiên cứu phân theo lần nhập viện điều trị

\begin{tabular}{|c|c|c|c|c|}
\hline & Chi phí trung bình & Tỷ lệ \% & LCI & HCI \\
\hline Điều trị lần đâu & & & & \\
\hline Chi phí cho đợt điều trị hiện tại & & & & \\
\hline Chi tiền túi hộ gia đình & 35.773 & $61,5 \%$ & 29.539 & 42.006 \\
\hline Chi phí BHYT & 22.393 & $38,5 \%$ & 18.026 & 26.758 \\
\hline
\end{tabular}


TAP CHÍ Y HOC VIÊT NAM TÂP 502 - THÁNG 5 - SỐ 1 - 2021

\begin{tabular}{|c|c|c|c|c|}
\hline Tống chi trực tiếp & 58.165 & $100,0 \%$ & 51.435 & 64.895 \\
\hline Tống chi phí trong năm 2019 & & & & \\
\hline Chi tiền túi hộ gia đình & 169.680 & $73,3 \%$ & 92.804 & 246.555 \\
\hline Chi phí BHYT & 61.736 & $26,7 \%$ & 51.435 & 64.895 \\
\hline Tống chi trực tiếp & 231.416 & $100,0 \%$ & 138.958 & 323.873 \\
\hline Điều trị tái phát & & & & \\
\hline Chi phí cho đợt điều trị hiện tại & & & & \\
\hline Chi tiền túi hộ gia đình & 34.627 & $65,7 \%$ & 24.375 & 44.878 \\
\hline Chi phí BHYT & 18.064 & $34,3 \%$ & 14.457 & 21.670 \\
\hline Tống chi trực tiếp & 52.690 & $100,0 \%$ & 41.172 & 64.208 \\
\hline Tống chi phí trong năm 2019 & & & & \\
\hline Chi tiền túi hộ gia đình & 172.219 & $67,1 \%$ & 102.173 & 242.266 \\
\hline Chi phí BHYT & 84.366 & $32,9 \%$ & 41.172 & 64.208 \\
\hline Tống chi trực tiếp & 256.585 & $100,0 \%$ & 164.204 & 348.965 \\
\hline Điều trị giai đoạn cuối & & & & \\
\hline Chi phí cho đợt điều trị hiện tại & & & & \\
\hline Chi tiền túi hộ gia đình & 20.160 & $64,9 \%$ & 13.389 & 26.931 \\
\hline Chi phí BHYT & 10.898 & $35,1 \%$ & 9.439 & 12.356 \\
\hline Tống chi trực tiếp & 31.058 & $100,0 \%$ & 24.353 & 37.763 \\
\hline Tống chi phí trong năm 2019 & & & & \\
\hline Chi tiền túi hộ gia đình & 178.548 & $67,5 \%$ & 104.251 & 252.845 \\
\hline Chi phí BHYT & 86.023 & $32,5 \%$ & 24.353 & 24.353 \\
\hline Tống chi trực tiếp & 264.571 & $100,0 \%$ & 159.362 & 369.779 \\
\hline
\end{tabular}

Bảng 3 mô tả giá trị $95 \%$ khoảng tin cây của tổng chi phí trực tiếp năm 2019 của người bệnh ung thư gan phân theo lần nhập viện điều trị. Với người bệnh nhập viện điều trị lần đâu, trung bình của tổng chi phí trực tiếp của đợt điều trị hiện tại là 58.165 .000 đồng, 95\% CI dao động từ 51.435.000 - 64.895.000 đồng. Chi phí tiền túi hộ gia đình trong đợt điều trị hiện tại trung bình là 35.773 .000 đồng, $95 \% \mathrm{CI}$ dao động từ 29.539.000 -42.006.000 đồng. Chi phí từ phía BHYT trong đợt điều trị hiện tại trung bình là 22.393.000 đồng, 95\%CI dao động từ 18.026.000 đồng đến 26.758 .000 đồng. Đối với tổng chi phí trong năm 2019, 95\% khoảng tin cậy của tổng chi phí trực tiếp rơi vào khoảng từ 138.958 .000 đồng đến 323.873 .000 đồng. Trong đó, $95 \%$ khoảng tin cậy của chi phí tiền túi hộ gia đình là 92.804.000 - 246.555.000 đồng. Tương tự đối với chi phí từ phía bảo hiểm y tế có $95 \%$ CI là 51.435.000 - 64.895.000 đồng.

Với người bệnh nhập viện điêu trị tái phát, trung bình của tổng chi phí trực tiếp của đợt điều trị hiện tại là 52.690 .000 đồng, 95\% CI dao động từ 41.172.000 đồng đến 64.208.000 đồng. Chi phí tiền túi hộ gia đình trong đợt điều trị hiện tại trung bình là 34.627.000 đồng, 95\%CI dao động từ 24.375 .000 đồng đến 44.878.000 đồng. Chi phí từ phía BHYT trong đợt điều trị hiên tại trung bình là 18.064.000 đồng, $95 \%$ CI dao động từ 14.457 .000 đồng đến
21.670 .000 đồng. Đối với tổng chi phí trong năm 2019, 95\% khoảng tin cậy của tổng chi phí trực tiếp rơi vào khoảng từ 164.204 .000 đồng đển 348.965 .000 đồng. Trong đó, $95 \%$ khoảng tin cậy của chi phí tiền túi hộ gia đình là 102.173.000 - 242.266.000 đồng. Tương tự đối với chi phí từ phía bảo hiểm y tế có $95 \%$ CI là 41.172 .000 - 64.208.000 đồng.

Với người bệnh nhập viện điêu trị giai đoạn cuối trung bình của tổng chi phí trực tiếp của đợt điều trị hiện tại là 31.058 .000 đồng, 95\% CI dao động từ 24.353.000 37.763 .000 đồng. Chi phí tiền túi hô̂ gia đình trong đợt điều trị hiện tại trung bình là 20.160.000 đồng, $95 \%$ CI dao động từ $13.389 .000-26.931 .000$ đồng. Chi phí từ phía BHYT trong đợt điều trị hiện tại trung bình là 4.668 .000 đồng, $95 \% \mathrm{CI}$ dao động từ 9.439.000 - 12.356.000 đồng. Đối với tổng chi phí trong năm 2019, 95\% khoảng tin cậy của tổng chi phí trực tiếp rơi vào khoảng từ 159.362.000 - 369.779.000 đồng. Trong đó, $95 \%$ khoảng tin cậy của chi phí tiền túi hộ gia đình là 104.251.000 - 252.845.000 đồng. Tương tự đối với chi phí từ phía bảo hiểm y tế có $95 \%$ CI là $24.353 .000-24.353 .000$ đồng.

\section{BÀN LUẬN}

Nghiên cứu cho thấy, trong đợt điều trị hiện tai, tổng chi phí trực tiếp vào khoảng 47.305.000 VNĐ với chi phí thấp nhất là 12.957 .000 VNĐ và 
chi phí cao nhất là 111.680.000 VNĐ. Đối với tổng chi phí trong năm 2019, tổng chi phí trực tiếp trung bình lên đến tổng chi phí trực tiếp vào khoảng 250.857.000 VNĐ với chi phí thấp nhất là 31.288.000 VNĐ và chi phí cao nhất là 1.291.727.000 VNĐ. Trong các nhóm chi phí, chi phí tiền túi hộ gia đình đều chiếm tỷ trọng lớn hơn. Nghiên cứu chi phí bệnh tật của ung thư được thực hiện nhiều tại các nước phát triển, đặc biệt là Mỹ். Một nghiên cứu gần đây tại Mỹ (6) đã ước tính tổng chi phí y tế trên quy mô quốc gia cho 13 nhóm bệnh ung thư ở nam giới và 16 nhóm bệnh ung thư ở nữ giới trong năm 2010 và dự báo tổng chi phí vào năm 2020, dựa trên các số liệu cập nhật nhất về tỷ lệ mới mắc, tỷ lệ sống sót và chi phí y tế. Trong đó, chi phí y tế của ung thư vú (nữ giới) là cao nhất (16.50 tỷ đôla $M y ̃)$, tiếp đến là ung thư đại trực tràng (14.14 tỷ đôla Mỹ), ung thư hạch (12.14 tỷ đôla Mỹ), ung thư phổi (12.12 tỷ đôla Mỹ) và ung thư tuyến tiền liệt (11.85 tỷ đôla Mỹ). Tại Việt Nam, nghiên cứu Đánh giá gánh nặng kinh tế của một số bệnh ung thư phổ biến được thực hiện từ năm 2012 tại các bệnh viện chuyên khoa tuyến trung ương và tuyến tỉnh/thành phố ở cả miền Bắc, miền Trung và miền Nam (5). Với góc độ tính toán chi phí từ cả phía chính phủ và hộ gia đình, nghiên cứu đề cập một cách toàn diện tất cả các nhóm chi phí. Kết quả nghiên cứu cho thấy, ung thư gan có chi phí điều trị trung bình trong năm 2012 là 162.620 .000 VNĐ $(95 \% \mathrm{CI}$ : 141.362.000 VND - 183.878.000 VND).

\section{KẾT LUÂ̂N}

Nghiên cứu cho thấy, trong đợt điều trị hiện tại, tổng chi phí trực tiếp vào khoảng 47.305.000 VNĐ với chi phí thấp nhất là 12.957.000 VNĐ và chi phí cao nhất là 111.680 .000 VNĐ. Đối với tổng chi phí trong năm 2019, tổng chi phí trực tiếp trung bình lên đến tổng chi phí trực tiếp vào khoảng 250.857.000 VNĐ với chi phí thấp nhất là 31.288.000 VNĐ và chi phí cao nhất là 1.291.727.000 VNĐ. Trong các nhóm chi phí, chi phí tiền túi hộ gia đình đều chiếm tỷ trọng lớn hơn.

\section{TÀI LIẸU THAM KHẢO}

1. Nguyễn Thanh Hương và công sư Báo cáo đề tài cấp bộ: Tuổi thọ khỏe mạnh và gánh nặng bênh tât tai Viêt Nam năm 2015, Hà Nôii.

2. Nguyến Thanh Hương và cộng sự Báo cáo đề tài cấp bộ: Tuổi thọ khỏe mạnh và gánh nặng bênh tật tại Việt Nam năm 2015, Hà Nôii.

3. Nguyền Thị Trang Nhung, Trân Khánh Long, Bưi Ngọc Lỉnh và cộng sự. (2010), Gánh nặng bệnh tật và chẫn thương ở Việt Nam, Nhà xuất bản y học, Hà Nỗi.

4. Bùi Diệu, Nguyển Bá Đức, Trân Văn Thuấn và công sự (2012). Gánh nặng bệnh ung thư và chiến lược phòng chống ung thư quốc gia đến năm 2020. Tạp Chí Ung Thư Học, 1, 13-19

5. Nguyển Quỳnh Anh và Nguyễn Thu Hà (2014), Báo cáo đề tài nghiên cứu cấp cơ sở: Gánh nậng kinh tế của 6 bệnh ung thư phố biến tai Viêt Nam,

6. Mariotto A.B., Robin Yabroff K., Shao Y. và công sự. (2011). Projections of the cost of cancer care in the United States: 2010-2020. J Natl Cancer Inst, 103(2), 117-128.

\title{
MÔ HÌNH BÊNH TÂT VÀ TỬ VONG TRẺ EM ĐIỀU TRI NộI TRÚ TẠI BÊ̂NH VIỆ̉N ĐA KHOA TİNH HÀ TĨNH GIAI ĐOẠN 2011-2019
}

\author{
Hoàng Quang Trung*, Dương Văn Giáp*, Trương Huy Hưng*, \\ Đặng Quang Minh*, Nguyễn Thị Liên*, Trần Thị Hương*, \\ Nguyễn Đình Phi*, Cao Thế Vinh* và cộng sự
}

\section{TÓM TẮT}

Đăt vấn đề: Mô hình bệnh tât và tử vong của một địa phương có vai trò quan trọng trong hoạch định chính sách chăm sóc sức khỏe cho địa phưởng đó. Hà tĩnh là một tỉnh miền Trung Bắc bộ, mô hình bệnh tật và tử vong ở đây có khác gì so với trẻ em trong cả nước. Để trả lời câu hỏi này, nghiên cứu xác

*Bênh viên Đa khoa tỉnh Hà Tïnh

Chịu trách nhiệm chính: Dương Văn Giáp

Email: drgiap9@gmail.com

Ngày nhận bài: 5.3.2021

Ngày phản biên khoa hoc: 22.4.2021

Ngày duyệt bài: 29.4.2021 đinh mô hình bênh tât trẻ em điều trị nôi trú tai Bênh viện Đa khoa tỉnh Hà Tĩnh giai đoạn 2011-2019 được tiển hành. Đối tượng nghiên cứu: Gồm hồ sơ 46.798 trẻ em điều trị nọi trú tai Bênh viên Đa khoa tỉnh Hà tĩnh trong giai đoạn này. Phương pháp nghiên cứu: Nghiên cứu hồi cứu, mô tả cắt ngang. Kết quả: Bệnh nhân nhi khoa chiếm 13,65\% so với bênh nhân toàn viên; Các nhóm bênh thường găp ở trẻ em là hô hấp 47,23\%; nhiễm khuẩn 18,31\%; tiêu hóa $15,95 \%$. Tỷ lệ tử vong trẻ em và tử vong toàn viện giảm dần, tử vong trẻ em từ 3,79\% (2011) giảm xuống $0,36 \%$ (2018), tử vong toàn viện từ 0,78\% (2011) xuống 0,12\% (2018). Tử vong trẻ em chiếm $57,09 \%$ tử vong toàn viên. Tử vong sơ sinh chiếm tỷ lệ $73,16 \%$ (gồm suy hố hấp sơ sinh, nhiễm khuẩn 